\title{
Residues of sulfonamides and their acetylated metabolites in the environment of aquaculture
}

\author{
Lei Tong ${ }^{1, *}$, Liting Qin ${ }^{1}$, Chuan Guan ${ }^{1}$, and Mesmire E. Wilson ${ }^{1}$ \\ ${ }^{1}$ School of Environmental Studies, China University of Geosciences, 430074 Wuhan City, China
}

\begin{abstract}
This study documents the occurrence of sulfonamides (SA) and their acetylated metabolite compounds in an aquaculture environment in China. Five parent compounds of SAs and four metabolites were detected in fish water, surface water, and groundwater. The most relevant compounds in terms of frequency of detection and maximum concentrations detected were sulfamethoxazole and sulfachinoxalin in fish water and surface water, with average concentrations of $541 \mathrm{ng} / \mathrm{L}$ and 274 $\mathrm{ng} / \mathrm{L}$, respectively. The acetylated metabolites were detected at higher concentrations than their parent compounds in groundwater, although they were much lower than in the surface environment. The recent appearance of acetylated metabolites of SAs in groundwater samples demonstrates the environmental health concern and the need of further study.
\end{abstract}

\section{Introduction}

Industrial aquaculture has been a rapidly growing industry in China in recent years. The last 20 years have seen a fourfold growth in industrial aquaculture worldwide [1]. However, the impressive development has been accompanied by potential pollution, such as veterinary drug residues in the environment. The occurrence of antibiotics has raised great concern as they have the potential to negatively affect non-target living organisms. These compounds are extensively used in both human and veterinary medicine against microbial infections. Sulfonamides (SAs) are one of the most widely used antibiotics in animal husbandry and fish farming [2]. Because SAs are fairly soluble in water and polar, they are likely to remain in groundwater and surface water after release. Residues of SAs have been detected in different water environments, such as municipal sewage, surface water and even groundwater [3]. So far, few studies have reported the residues of metabolites in the environment, especially acetylated metabolites of SAs. It is known that the metabolism of SAs involves acetylation and oxidation at the $\mathrm{N}^{4}$-nitrogen atom, leading to $\mathrm{N}^{4}$-acetyl and $\mathrm{N}^{4}$-hydroxy SAs [4]. They are mainly metabolized in the liver, but also in other tissues. It is reported that the metabolite was more toxic than its parent compound, sulfapyridine ${ }^{2}$. Therefore, the occurrence of metabolites in the environment is important for antibiotic pollution control.

Study of the presence and the fate of metabolites of SAs in the environment has just started in developed countries. Concentrations of $\mathrm{N}^{4}$-acetylsulfamethoxazole have been

\footnotetext{
*Corresponding author: tonglei@ cug.edu.cn
} 
found at higher concentrations than the parent sulfamethoxazole in surface waters [4]. To better assess the occurrence of SAs and their metabolites in aquaculture, five different sulfonamides and their respective acetylated metabolites were investigated in Honghu Lake, central China.

\section{Materials and methods}

\subsection{Chemicals and standards}

Sulfapyridine (SPD), sulfadiazine (SDZ), sulfamethazine (SMZ), sulfamethoxazole (SMX), Sulfachinoxalin (SQX) were purchased from Dr. Ehrenstorfer (Augsburg, Germany), N ${ }^{4}$ acetyl-sulfamethoxazole (AcSMX), $\mathrm{N}^{4}$-acetyl-sulfamerazine (AcSMR), $\mathrm{N}^{4}$-acetylsulfamethazine (AcSMZ) and $\mathrm{N}^{4}$-acetyl-sulfadiazine (AcSDZ) were purchased from Toronto Research Chemicals (Ontario, Canada). HPLC-grade solvents were supplied by Merck (Darmstadt, Germany). Individual antibiotic stock standard solutions were prepared at $1000 \mu \mathrm{g} / \mathrm{mL}$ by dissolving $10 \mathrm{mg}$ of the individual compound in $10 \mathrm{~mL}$ methanol $(\mathrm{MeOH})$. Metabolite standard solutions were prepared at $100 \mu \mathrm{g} / \mathrm{mL}$ by dissolving $1 \mathrm{mg}$ of the individual compound in $10 \mathrm{~mL}$ methanol $(\mathrm{MeOH})$. A $10 \mu \mathrm{g} / \mathrm{mL}$ stock standard solution of the mixture of all compounds was made up by mixing. Solutions were transferred to amber bottles and stored in the dark at $-20{ }^{\circ} \mathrm{C}$ to minimize potential analyte degradation. Ultrapure water was used in the analysis, which was purified using a Milli-Q system at 18.2 $\mathrm{M} \Omega \mathrm{cm}^{-1}$.

\subsection{Study area and sampling}

Honghu Lake, is a lake along the Yangtze River in China and plays a very important role as drinking, agricultural, aquacultural and industrial water sources. It is the largest natural wetland on the Jianghan plain of Hubei Province, with a surface area of $348 \mathrm{~km}^{2}$ and average depth of $1.35 \mathrm{~m}$ (Fig. 1). The area has a subtropical monsoon climate, rainfall range of 1100 to $1300 \mathrm{~mm}$, and annual mean temperature of $16.3{ }^{\circ} \mathrm{C}$. In this area, 20 groundwater samples from private wells, 9 surface water samples (from Honghu Lake and connected rivers) and 4 water samples from fish ponds were collected in December 2015.

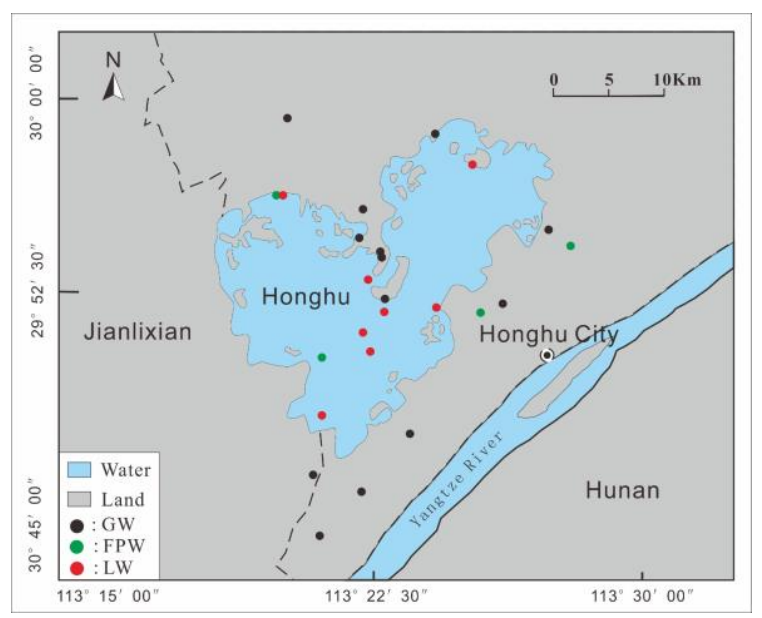

Fig. 1. Location map showing the sample sites for this study (GW: groundwater; FPW: fish pond water; LW: lake water). 


\subsection{Samples pre-treatment and analysis}

Water samples were extracted using a 12-port vacuum manifold solid-phase extraction (SPE) system (Supelco, USA). Sample extraction was performed and modified based on a previous study [5]. For mass spectrometric analyses, the spray voltage was set to $3800 \mathrm{~V}$, vaporizer temperature was $250{ }^{\circ} \mathrm{C}$, sheath gas pressure and aux gas pressure were set to 40 psi and 10 psi, respectively. Quantification of the targets was achieved by multiple reaction monitoring (MRM) detection. For MS detection, the instrument was operated in positive for all compounds. The measures for validating the analytical methods are listed in Table 1.

Table 1. Optimized instrumental conditions for targets determination.

\begin{tabular}{|c|c|c|c|c|c|}
\hline Compounds & {$[\mathbf{M}+\mathbf{H}]^{+}$} & $\begin{array}{l}\text { Retention } \\
\text { time (min) }\end{array}$ & $\begin{array}{c}\text { MRM } \\
\text { transitions }\end{array}$ & $\begin{array}{c}\text { Collision } \\
\text { Energy (V) }\end{array}$ & $\begin{array}{l}\text { Tube } \\
\text { Lens }\end{array}$ \\
\hline \multirow[t]{2}{*}{ Sulfamethazine (SMZ) } & 279.1 & 2.57 & $279 / 108$ & 12 & 63 \\
\hline & & & 279/191 & 78 & 63 \\
\hline \multirow[t]{2}{*}{ Sulfadiazine (SDZ) } & 251.1 & 1.81 & $251 / 156$ & 15 & 60 \\
\hline & & & $251 / 185$ & 16 & 60 \\
\hline \multirow[t]{2}{*}{ Sulfapyridine (SPD) } & 250.2 & 2.23 & $250 / 91$ & 20 & 71 \\
\hline & & & $250 / 239$ & 11 & 71 \\
\hline \multirow[t]{2}{*}{ Sulfachinoxalin (SQX) } & 301.1 & 4.04 & $301 / 141$ & 13 & 83 \\
\hline & & & $301 / 292$ & 9 & 83 \\
\hline \multirow[t]{2}{*}{ Sulfamethoxazole (SMX) } & 254.1 & 3.49 & $254 / 215$ & 16 & 61 \\
\hline & & & $254 / 243$ & 10 & 61 \\
\hline \multirow{2}{*}{$\begin{array}{l}\mathrm{N}^{4} \text {-acetyl-sulfamethoxazole } \\
(\text { AcSMX) }\end{array}$} & 296.1 & 4.79 & $296 / 185$ & 20 & 236 \\
\hline & & & $296 / 287$ & 11 & 236 \\
\hline \multirow{2}{*}{$\begin{array}{l}\mathrm{N}^{4} \text {-acetyl-sulfamerazine } \\
(\text { AcSMR) }\end{array}$} & 307.1 & 2.51 & $307 / 185$ & 23 & 73 \\
\hline & & & $307 / 299$ & 6 & 73 \\
\hline \multirow{2}{*}{$\begin{array}{l}\mathrm{N}^{4} \text {-acetyl-sulfamethazine } \\
\text { (AcSMZ) }\end{array}$} & 321.1 & 2.66 & $321 / 295$ & 23 & 76 \\
\hline & & & $321 / 313$ & 5 & 76 \\
\hline \multirow{2}{*}{$\begin{array}{l}\mathrm{N}^{4} \text {-acetyl-sulfadiazine } \\
\text { (AcSDZ) }\end{array}$} & 293.1 & 2.3 & $293 / 118$ & 19 & 55 \\
\hline & & & $293 / 185$ & 16 & 55 \\
\hline
\end{tabular}

\section{Results and discussion}

\subsection{Concentration of SAs and their metabolites in fish water and surface water}

The results of SAs and their metabolite residues in the aquaculture environment are shown in Figure 2. Among the detected targets, SMZ, SMX, SQX, AcSDZ and AcSMX were found in all fish water and surface water samples. The highest concentrations (average value of different sampling sites) detected were for SMX at $541 \mathrm{ng} / \mathrm{L}$ and $274 \mathrm{ng} / \mathrm{L}$ in fish water and surface water, respectively. In accordance with previous studies, SMX was among the most frequently detected sulfonamides and had relatively high concentration in the environmental water samples [6]. Besides parent compounds of SAs, three metabolites (AcSMR, AcSMZ and AcSMX) were found at concentrations higher than $100 \mathrm{ng} / \mathrm{L}$ in fish water. Combined with the frequency results, AcSMR and AcSMX should be considered as "dangerous compounds" as a guide in future work. In previous studies, the $\mathrm{N}^{4}$-acetyl sulfamethoxazole usually accounted for greater than $50 \%$ of an administered dose in human 
excretion and can occur in WWTP influents at concentrations 2.5 to 3.5 times higher than concentrations of the parent compound [6].

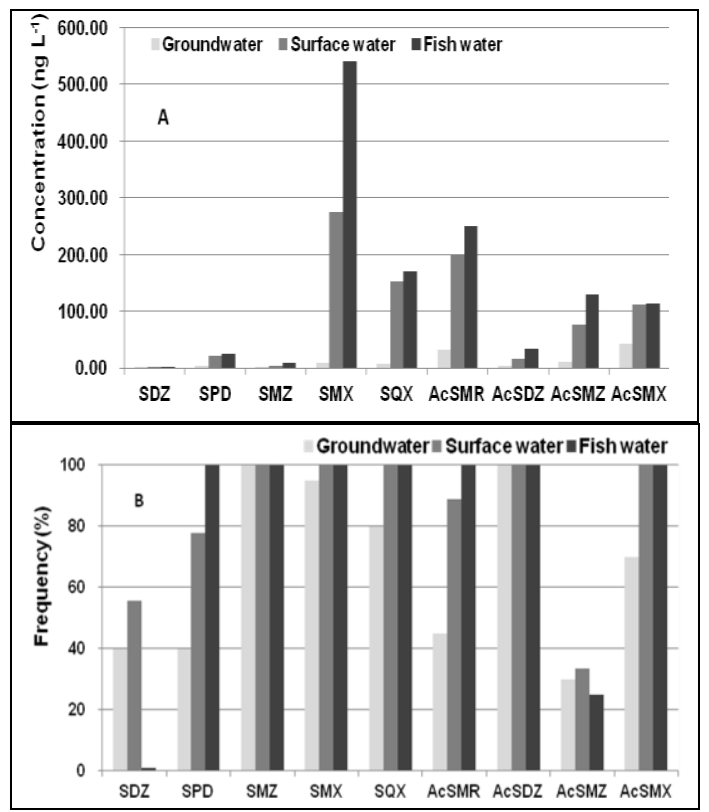

Fig. 2. SAs and their acetylated metabolites in different environmental waters (A) average concentration; (B) detection frequencies).

\subsection{Concentration of SAs and their metabolites in groundwater}

To understand the influence of aquaculture pollution on groundwater, twenty samples were collected from private wells; residues of SAs and their metabolites were detected in the samples. The concentrations of targets in groundwater were much lower than that in fish pond water and surface water samples. However, most detection frequencies of these compounds in groundwater were more than $60 \%$. From the results, SMZ and AcSDZ were found in all groundwater samples, the same as for fish water and surface water. The highest residue compounds found were AcSMR and AcSMX, although concentrations were only $32 \mathrm{ng} / \mathrm{L}$ and $42 \mathrm{ng} / \mathrm{L}$, respectively. It was interesting that metabolites were found in higher concentrations than their parent compounds in groundwater. For example, AcSMZ was also detected at a higher concentration than SMZ in groundwater as it was in fish water and surface water.

\section{Conclusions}

Sulfonamide antibiotics were detected in fish pond water, surface water and adjacent groundwater. Five SAs parent compounds and four acetylated metabolite compounds in 33 samples were investigated. Most targets were shown with high detection frequencies in all water samples. Compared to fish pond water and surface water, groundwater was in general less contaminated, with concentrations ranging from 0.3 to $42.1 \mathrm{ng} / \mathrm{L}$. However, acetylated metabolite compounds were detected in several groundwater samples at higher concentration levels than in samples from the surface environment. The results of this study are valuable for understanding possible metabolite compounds of antibiotics in the 
environment. More routine groundwater monitoring should be performed to investigate these kinds of metabolite compounds.

This work was financially supported by National Natural Science Foundation of China (No. 41772364 and 41521001).

\section{References}

1. F.C. Cabello, Env Microbiol, 8, 1137-1144 (2006)

2. M.J. Garcia-Galan, et al., Sci Total Env, 409, 5505-5512 (2011)

3. M.J. Garcia-Galan, et al., Trend Anal Chem, 27, 1008-1022 (2008)

4. D. Ashton, et al., Sci Total Env, 333, 167-184 (2004)

5. L. Tong, et al., Sci Total Env, 497-498, 180-187 (2014)

6. N. Le-Minh, et al., Water Res, 44, 4295-4323 (2010) 